\title{
Produção de tijolos prensados com agregados reciclados da construção civil
}

O setor da construção civil provoca grandes impactos ambientais decorrentes de suas atividades, sendo que a elevada geração de resíduos, denominados de Resíduos da Construção Civil (RCC), e está associada a várias problemáticas críticas e urgentes no contexto urbano. Este artigo, fruto da dissertação de mestrado em Ambiente e Desenvolvimento, realizado no Programa de Pós-Graduação do Univates Centro Universitário - RS, evidencia a possibilidade do reaproveitamento deste material (RCC) como alternativa de incorporá-lo na fabricação de tijolos, com o objetivo de realizar a utilização dos resíduos da construção civil. Para viabilizar a produção de tijolo prensado, foram utilizados Agregados Reciclados da Construção Civil (RCC). A partir das informações e dados levantados, foram estudadas as legislações vigentes priorizando o tema, com ênfase nos instrumentos legais estipulados para a gestão ambiental de RCC. Os tijolos prensados com RCC foram utilizados na execução de alvenarias de vedações, tendo como objetivo proporcionar um destino adequado ao RCC, a fim de contribuir com a sustentabilidade na construção, atenuando, assim, os problemas enfrentados pelos órgãos ambientais e sociais. Para a caracterização dos materiais, foram realizados ensaios laboratoriais, conforme as normas: ensaios de análise granulométrica, ensaios de compressão simples de absorção de água e capilaridade. Foi utilizado o solo miúdo onde se escolheu a porcentagem com teor de argamassa (51\%), aplicando nos traços definidos (1:7, 1:9, 1:11 e 1:20). Foram produzidos tijolos com RCC que foram analisados e testados numa primeira etapa nas idades de $07,14,28$ dias, sendo que o final dos estudos ocorreu na idade de 180 dias, conforme as normas estabelecidas de ensaios para a absorção de água por imersão, absorção de água por capilaridade, resistência à compressão axial simples entre outros.

Palavras-chave: Resíduos da construção civil; Reaproveitamento; Produção de Tijolos Prensados de (RCC).

\section{Production of pressed bricks with recycled aggregates from civil construction}

\begin{abstract}
The construction sector causes major environmental impacts resulting from its activities, and the high generation of waste, called Civil Construction Waste (CCR), is associated with several critical and urgent problems in the urban context. This article, the result of the master's thesis in Environment and Development, carried out in the Graduate Program of the University Center Univates - RS, evidences the possibility of reusing this material (CCR) as an alternative to incorporate it in the manufacture of bricks, with the objective of performing the use of civil construction waste. To enable the production of pressed brick, recycled aggregates of civil construction $(\mathrm{Ccr})$ were used. Based on the information and data collected, the current legislations were studied prioritizing the theme, with emphasis on the legal instruments stipulated for the environmental management of CCR. The bricks pressed with CCR were used in the execution of fence masonry, aiming to provide an appropriate destination for the CCR, in order to contribute to sustainability in construction, thus mitigating the problems faced by environmental and social agencies. To characterize the materials, laboratory tests were carried out according to the following standards: granulometric analysis tests, simple compression tests of water absorption and capillarity. The small soil was used where the percentage with mortar content (51\%) was chosen, applying in the defined traits (1:7, 1:9, 1:11 and 1:20). Bricks were produced with CMR that were analyzed and tested in a first stage at the ages of $07,14,28$ days, and the end of the studies occurred at the age of 180 days, according to the established standards of tests for water absorption by immersion, water absorption by capillarity, simple axial compressive strength among others.
\end{abstract}

Keywords: Construction waste; Reuse; Production of Pressed Bricks (RCC).

Topic: Construções e Arquitetura Sustentáveis

Reviewed anonymously in the process of blind peer.
Received: 04/03/2021

Approved: 23/03/2021
Eduardo Miranda Ethur (iD

Universidade do Vale do Taquari, Brasil http://lattes.cnpq.br/0536800052883688

http://orcid.org/0000-0003-1731-3778

eduardome@univates.br

Juzélia Santos da Costa (iD

Universidade Federal de São Carlos, Brasil http://lattes.cnpq.br/3645611454529061 http://orcid.org/0000-0002-0385-5528 juzelia.costa@cba.ifmt.edu.br

Benedito Ilmar de Moraes (iD)

Universidade do Vale do Taquari, Brasil

http://lattes.cnpq.br/7663676128351397

http://orcid.org/0000-0001-7688-8745

ditoilmar@hotmail.com
Referencing this:

ETHUR, E. M.; COSTA, J. S.; MORAES, B. I.. Produção de tijolos prensados com agregados reciclados da construção civil. Revista Ibero Americana de Ciências Ambientais, v.12, n.3, p.182-192, 2021. DOI: http://doi.org/10.6008/CBPC2179-6858.2021.003.0017 


\section{INTRODUÇÃO}

Segundo Nagalli (2014), a construção civil brasileira vem aumentando sua participação na economia nacional. Cerca de $20 \%$ do PIB brasileiro vem deste setor, o que o torna um dos mais importantes ramos de produção do país.

Igualmente, nestas últimas décadas, os resíduos da construção civil (RCC) vêm recebendo atenção crescente por parte de construtores e pesquisadores em todo o mundo (YUAN et al., 2012). Isso se deve, principalmente, ao fato de que os RCCs estão se tornando um dos principais agentes para a poluição ambiental (YUAN et al., 2011; JAILON et al., 2009).

Nesse cenário, a construção civil, nos moldes como é hoje conduzida, apresenta-se como grande geradora de resíduos. No Brasil, onde boa parte dos processos construtivos é essencialmente manual e cuja execução se dá praticamente no canteiro de obras, os resíduos de construção e de demolição, além de potencialmente degradadores do meio ambiente, ocasionam problemas logísticos e prejuízos financeiros.

Conforme estimativa da Associação Brasileira de Empresas de Limpeza Pública e Resíduos Especiais (ABRELPE), em 2012, os municípios brasileiros coletaram mais de 35 milhões de toneladas de RCCs, o que representa 55\% de todo o resíduo sólido urbano (RSU) coletado naquele ano. A União Europeia, preocupada com essa questão, estipulou a meta ousada de recuperar $70 \%$ em peso dos resíduos de construção civil (RCC) até 2020 (LLATAS, 2011).

O Plano Nacional de Resíduos Sólidos estabelece como meta que todas as regiões do país estejam aptas a reciclar seus resíduos utilizando unidades de recuperação, com eliminação das áreas de disposição irregular (bota-foras).

Assinala-se que esse tema ganhou grande importância nas últimas décadas, mas as pesquisas na área ocorrem ainda de maneira dispersa. Yuan et al. (2011), ao pesquisarem as publicações disponíveis sobre o assunto, concluíram que a investigação sobre os resíduos da construção civil ainda não é sistemática e carece de aprofundamento e padronização.

Outra dificuldade citada se refere ao fato de que as pesquisas recentes sobre os resíduos da construção civil são essencialmente sobre coleta de dados e de cunho descritivo (YUAN et al., 2011). Ainda assim, vislumbra-se a perspectiva de que as pesquisas se voltem mais para técnicas de simulação e moldagem mais sofisticadas.

Entre os Centros de Pesquisas Importantes em RCCs estão The Hong Kong Polytechnic University e City University of Hong Kong (China); University Kebangsaan Malaysia (Malaysia); Griffith University e University of Western Sydney (Australia); e National Technical University of Athena's (Grécia).

No Brasil, o interesse em pesquisar o Campo dos Resíduos da construção civil também se manifesta. Em Cuiabá, pesquisadores do Campus Octayde Jorge da Silva (IFMT) vêm desenvolvendo pesquisas com esse objetivo, figurando, entre outros, os estudos com tijolos de Solo-Cimento, com Agregados Reciclados de Resíduos de Cerâmica Vermelha (RCV) para Concretos e Argamassas (COSTA et al., 2008) e (FAVINI et al., 2009), com Resíduos da Construção Civil (RCC), para Blocos de Alvenaria, (RCC) para Concreto Auto Adensável 
(LIMA et al., 2012), e (RCC) para Base, Sub-Base de Pavimentos (AMORIM et al., 2011).

Seguindo esse interesse em pesquisar o reaproveitamento de resíduos da construção civil com intuito de contribuir para o fortalecimento de estudos nessa área em Mato Grosso, este presente trabalho objetiva produzir um tijolo prensado de agregados reciclados da construção civil (RCC), materiais oriundos de uma concessionária, no município de Cuiabá-MT. No desenvolvimento de produção desse tijolo prensado, pretende-se explorar as potencialidades do resíduo (RCC) que, hoje, são descartados na natureza de forma sustentável.

\section{MATERIAIS E MÉTODOS}

\section{Fabricações dos Tijolos}

Para fabricação dos tijolos, utilizou-se o método do Helene (1993), adaptados por Costa (2006).

Trata-se do proporcionalmente adequado dos materiais constituintes - cimento, agregado miúdo, agregado graúdo, água e eventualmente aditivos - atendendo as características básicas do estudo de dosagem, com base nos requisitos de obra e de projeto. Na determinação do teor de argamassa ideal, usase o traço, ou seja, testar os teores de argamassa crescentes até identificar o teor que resulta na trabalhabilidade desejada com boa coesão do concreto, sem exsudação e sem segregação.

Os procedimentos utilizados na fabricação dos tijolos foram: peneiramento do agregado retirado da empresa em estudo direto do britador, adição do cimento e água, com um teor de argamassa de 51\%, para formar a massa (farofa) nas proporções dos traços em volume 1:7 em massa: (1:3,08:3,92); 1:9 em massa $(1: 4,1: 4,9) ; 1: 11$ em massa $(1: 4,61: 6,39)$ e $1: 20(1: 9,71: 10,29)$, respectivamente: cimento e agregado de resíduo da construção civil, (conforme figuras 17, 18, 19, 20, 21 e 22). Nessa etapa, os tijolos foram estudados nas idades de 7, 14 e 28 dias e, na fase final da pesquisa, os tijolos foram avaliados na idade de 180 dias. Os tijolos possuem as seguintes dimensões: $250 \mathrm{~mm}$ de comprimento $125 \mathrm{~mm}$ de largura e $62,5 \mathrm{~mm}$ de altura.

Para prensagem dos tijolos, utilizou-se uma prensa hidráulica em que foram fabricados 12 tijolos por idade. A cura dos tijolos ocorreu em câmara úmida coberta com lona preta por um período de 07 dias, sendo molhado uma vez ao dia, conforme as informações técnicas da NBR-8492:2012.

\section{Propriedades físicas dos Tijolos no estado endurecido}

Determinação da absorção de água por imersão - Índice de vazios e massa específica de acordo com a Norma brasileira NBR 9778:2009 - Argamassa e concreto endurecidos - Determinação da absorção de água, índice de vazios e massa específica (ABNT, 2001).

\section{Absorção água por imersão NBR 9778:2009}

A absorção de água por imersão é o procedimento que faz com que a água tende a se conduzir para os poros permeáveis de determinado corpo poroso com o intuito de preenchê-los. Equação 1.

Definida pela seguinte Equação: 


$$
A=\frac{M_{\text {sat }}-M_{S} \times 100}{M_{S}}
$$

Equação 1

Onde:

$\mathrm{AA}=$ Absorção de água por Imersão Msat $=$ Massa do corpo-de-prova saturado $\mathrm{Ms}=$ Massa do corpo-de-prova seco em estufa

\section{Índice de vazios}

Como não há previsão de cálculo do índice de vazios e da porosidade nas normas de solo-cimento, no presente trabalho utilizaram-se os parâmetros determinados por Pinto (2016). Como a massa específica dos grãos de solo e dos grãos de cimento já foram determinadas em outros ensaios, alternativamente o índice de vazios pode ser determinado sem necessidade da balança hidrostática, conforme demonstrado nas equações:

$$
\begin{aligned}
& e_{r c c}=\frac{(1+p)}{\delta_{r c c-c}\left(\frac{1}{\delta_{r c c}}+\frac{p}{\gamma_{c}}\right)} \text { (índice de vazios) Equação } 2 \\
& n_{r c c}=\left[1-\frac{\delta_{r c c-c}\left(\frac{1}{\delta_{r c c}}+\frac{p}{\gamma_{c}}\right)}{(1+p)}\right] \times 100 \% \text { (porosidade) Equação } 3
\end{aligned}
$$

Dados:

P - Proporção de cimento em relação ao agregado reciclado - (RCC) seco, grama. Srcc-c = Massa específica aparente do RCC (Resíduo da Construção Civil) mais cimento, $\mathrm{g} / \mathrm{cm}^{3}$ $\delta$ rcc - Massa específica do agregado reciclado (RCC), $\mathrm{g} / \mathrm{cm}^{3}$ Yc - Massa específica do cimento, $\mathrm{g} / \mathrm{cm}^{3}$ $($ ercc-c) $=$ Índice de vazios do agregado reciclado $-(\mathrm{RCC})$ com cimento

$(\mathrm{nrcc}-\mathrm{c})=$ Porosidade do agregado reciclado $-(\mathrm{RCC})$ com cimento

\section{Massa Específica (NBR 9778:2009) - em g/cm³}

A massa específica é a relação entre a massa seca do material e o volume total, incluindo todos os poros permeáveis e impermeáveis, e a massa específica real é a mesma relação, excluindo os poros permeáveis. Equação 4.

Calcular da massa específica da amostra seca $(\rho s)$ pela seguinte Equação 4

$$
\rho s=\frac{M_{s}}{M_{\text {sat }}-M_{i}} \quad \text { Equação } 4
$$

\section{Massa específica da amostra saturada em $\mathrm{g} / \mathrm{cm}^{3}$}

Calcular a massa específica da amostra saturada após fervura ( $\rho$ sat) pela seguinte Equação 5.

$$
\boldsymbol{\rho} \text { sat }=\frac{M_{\text {sat }}}{M_{\text {sat }}-M_{\mathrm{i}}}
$$




\section{Onde: \\ $\rho$ sat - massa específica da amostra saturada \\ Msat - massa do corpo de prova saturado \\ $\mathrm{Mi}$ - massa do corpo de prova saturado, imerso em água}

\section{Massa específica real em $\mathrm{g} / \mathrm{cm}^{3}$}

Calcular a massa específica real da amostra ( $\rho r)$, pela seguinte Equação 6:

$$
\boldsymbol{\rho} r=\frac{M_{S}}{M_{s}-M_{i}} \quad \text { Equação } 6
$$

Onde:

$\rho r$ - massa específica real

$\mathrm{Mi}$ - massa do corpo de prova saturado, imerso em água

Ms - massa do corpo de prova seco em estufa

Determinação da absorção da água por capilaridade - Método de ensaio. Norma brasileira NBR 9779:2012 - Argamassa e concreto endurecidos - Determinação da absorção de água por capilaridade

A NBR 9779:2012 prescreve o método para determinação da absorção de água, através da ascensão capilar, de argamassa e concreto endurecidos. A absorção de água por capilaridade deve ser expressa em $\mathrm{g} / \mathrm{cm}^{2}$ e calculada dividindo o aumento de massa pela área da seção transversal da superfície do corpo-deprova em contato com a água, de acordo com a seguinte equação (7).

A absorção de água por capilaridade é calculada de acordo com a Equação 7.

$$
C=\frac{M_{\text {sat }}-M_{S}}{s} \quad \text { Equação } 7
$$

Onde:

C é a absorção de água por capilaridade, expressa em gramas por centímetro quadrado (g/cm2); msat é a massa saturada do corpo de prova que permanece com uma das faces em contato com a água durante um período de tempo especificado, expressa em gramas (g); $m s$ é a massa do corpo de prova seco, assim que este atingir a temperatura de $(23 \pm 2){ }^{\circ} \mathrm{C}$, expressa em gramas (g); $\underline{S \text { é a área da seção transversal, expressa em centímetros quadrados (cm2) }}$

\section{Resistência mecânica à compressão simples}

Define-se a resistência de um material como a sua capacidade de resistir à tensão sem ruptura. Em um corpo de prova, é a carga máxima que este pode suportar.

Ensaio de resistência à compressão simples dos tijolos ecológicos de acordo com a NBR 8492:2012. Para o rompimento, os tijolos deverão estar com as faces planas, o que é feito capeando as faces com pasta de cimento Portland de consistência plástica, com espessura mínima de $3 \mathrm{~mm}$.

Todos esses procedimentos foram realizados para a obtenção de um micro concreto suficientemente homogêneo e compacto, cuja avaliação será conforme a fabricação dos tijolos de agregados reciclados da construção.

\section{RESULTADOS E DISCUSSÃO}

Na Figura 1 estão representados os resultados dos ensaios de caracterizações dos agregados reciclados da construção civis e demolições $(R C D)$, utilizadas na pesquisa para produção dos tijolos. Trata-se da curva granulométrica do agregado miúdo utilizado em estudo. 


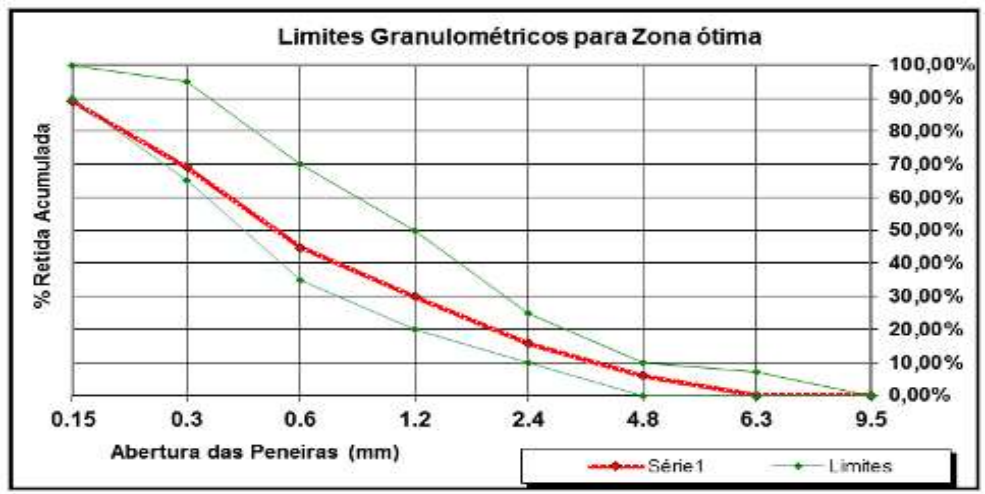

Figura 1: Composição Granulométrica do Agregado Miúdo.

Diâmetro máximo: 6,3 mm

Módulo de finura: 2,55

O ensaio para determinação do teor de torrões de argila e materiais friáveis foi realizado de acordo com que estabelece a NBR 7218:2010. Na Tabela 1, constam os percentuais encontrados do agregado miúdo reciclado dos resíduos sólidos da construção civil e demolição respectivamente exigida pela NBR 15116:2004 (ABNT, 2004). Pode-se observar que a média do teor de torrões de argila e materiais friáveis para o resíduo miúdo ficou acima do exigido pela norma. Isso pode ter sido influenciado pelas características do material que apresenta em sua composição grande parcela de material cerâmico, alvenaria, concretos e outros, e ainda podem ter ocorrido falhas no processamento de trituração e moagem do material, e isso pode ser outro fator contribuinte para esse resultado. Analisando a média dos resultados dos ensaios para o agregado miúdo reciclado, é possível observar que a porcentagem de teor de torrões de argila e materiais friáveis não atendeu ao parâmetro de $2 \%$ aceitável pela norma.

Tabela 1: Teor de torrões de argila.

\begin{tabular}{|l|l|l|l|l|l|}
\hline Passante & Retido & Amostra Ensaiada & $\begin{array}{l}\text { Peneira } \\
\text { depois/lavagem } \\
\text { amostra }\end{array}$ & $\begin{array}{l}\text { Amostra Peneirada } \\
\text { Seca }\end{array}$ & Amostra Retida em \% \\
\hline 4,47 & 1,18 & $200 \mathrm{~g}$ & 600 & 185,2 & $7 \%$ \\
\hline 9,5 & 4,75 & $1 \mathrm{Kg}$ & 2,36 & 960,5 & $4 \%$ \\
\hline 19 & 9,5 & $2 \mathrm{Kg}$ & 4,75 & 1947,2 & $3 \%$ \\
\hline
\end{tabular}

O ensaio consistiu em preparar uma argamassa contendo os ARTC e o cimento Portland CP V, que possui alta concentração alcalina para acelerar o processo das barras de argamassa nas condições do ensaio diante dos limites da exposição estabelecida pela norma de 0,19\%.

O traço utilizado para a argamassas foi o 1: 2,25 (aglomerante: ARTC) e uma relação água/cimento igual a 0,47 (NBR 15577-4: 2008). As quantidades necessárias para moldagem de três barras para cada argamassa, e as granulometrias utilizadas dos ARTC estão, respectivamente, transcritas na Tabela 2.

Tabela 2: Granulometria requerida do material para ensaio.

\begin{tabular}{|l|l|l|}
\hline \multicolumn{2}{|l|}{ Porcentagem de Materiais (agregados) } & Percentagem (\%) \\
\hline Peneiras & 10 & Percentagem (\%) \\
\hline $4,8 \mathrm{~mm}$ e $2,4 \mathrm{~mm}$ & 25 & 99 \\
\hline $2,4 \mathrm{~mm}$ e $1,2 \mathrm{~mm}$ & 25 & 247,5 \\
\hline $1,2 \mathrm{~mm}$ e $0,600 \mathrm{~mm}$ & 25 & 247,5 \\
\hline $0,600 \mathrm{~mm}$ e $0,300 \mathrm{~mm}$ & 15 & 247,5 \\
\hline $0,300 \mathrm{~mm}$ e $0,150 \mathrm{~mm}$ & \multicolumn{2}{l}{148,5} \\
\hline
\end{tabular}




\begin{tabular}{|l|l|}
\hline Cimento: Portland CP V \\
\hline Materiais cimentícios & Agregados reciclados \\
\hline Traço & $1: 2,25$ \\
\hline Relação equivalente água/cimento & 0,47 \\
\hline Comprimento nominal da barra $(\mathrm{mm})$ & 285 \\
\hline
\end{tabular}

A argamassa foi misturada manualmente e depois foram moldados os corpos de prova, confeccionadas três barras prismáticas, de seção quadrada, com $25 \mathrm{~mm}$ de lado e $285 \mathrm{~mm}$ de comprimento, com duas camadas adensadas com 20 golpes de soquete.

Os moldes foram colocados em câmara úmida por $24 \mathrm{~h}$ e, em seguida, foram desmoldadas e colocadas submersas em água destilada a $80^{\circ} \mathrm{C}$ por outras $24 \mathrm{~h}$.

Retiradas da água, foi feita leitura do comprimento inicial e, em seguida, submersas na solução de $\mathrm{NaOH} 1 \mathrm{~N}$ (Hidróxido de sódio 1 Normal) a 80 ㄷ. Após a leitura zero (leitura inicial), foram efetuadas leituras nas idades de 16 e 30 dias, e três leituras intermediárias em cada período.

Expansões inferiores a 0,10\% aos 16 dias de idade indicam um comportamento inócuo do agregado na maioria dos casos; expansões superiores a $0,10 \%$ e inferiores a $0,20 \%$ aos 16 dias de idade indicam um comportamento potencialmente reativo; expansões superiores a $0,20 \%$ aos 16 dias de ensaio indicam um comportamento reativo do agregado, ASTM C-1260.

Conforme a Norma da ABNT NBR 15577-4, quando o resultado do ensaio de álcali-agregado pelo método acelerado indicar o limite de expansão for menor de 0,19\% aos 30 dias de cura em solução alcalina, o agregado reciclado é considerado potencialmente inócuo para uso em concreto. Conforme o resultado apresentado na Figura 2, a porcentagem da expansão aos 16 dias foi de 0,098 \% e aos 30 dias foi de 0,164 \%.

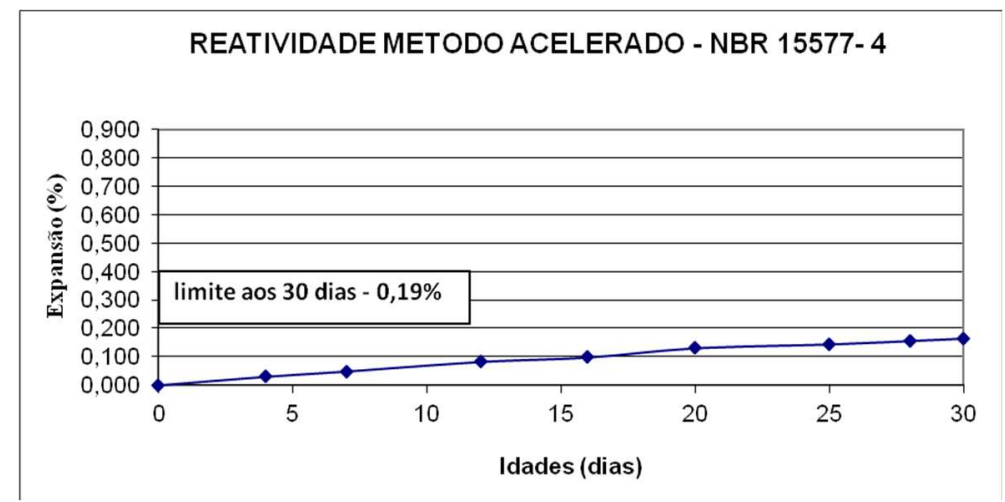

Figura 2: Determinação da Reatividade álcali-Agregado pelo Método Acelerado.

\begin{tabular}{|l|l}
\hline Expansão (\%) 16 dias & $=0,098$ \\
\cline { 1 - 1 } Expansão (\%) 30 dias & $=0,164$
\end{tabular}

Conforme a Norma da ABNT NBR 15577 e ASTM C-1260, os resultados apresentados no gráfico 09 e na investigação acima, conclui-se que o agregado reciclado do resíduo da construção civil (RCC) tem predisposição para uso na indústria da construção civil.

Nas literaturas pesquisadas sobre os agregados reciclados da construção civil, vários autores fazem referências às atividades pozolânicas das partículas mais finas, manifestadas na presença de componentes de cal e cimento. Para constatar essas propriedades, foi providenciado o ensaio que determina o Índice de Atividade Pozolânica com o cimento. 
Trata-se de um método físico para determinar o índice de Atividade Pozolânica, que se realiza misturando duas partes do material fino do Agregado Reciclado; uma parte de hidróxido de cálcio puro $\left[\mathrm{Ca}(\mathrm{OH})_{2}\right]$ numa argamassa composta com 9 partes em massa de areia normal, observando-se a adição de água para que a argamassa atinja uma consistência de $225 \pm 5 \mathrm{~mm}$.

Após a moldagem em corpos-de-prova cilíndricos de $50 \mathrm{~mm}$ de diâmetro por $100 \mathrm{~mm}$ de altura, as argamassas são submetidas à cura por 28 dias, sendo que as primeiras $24 \pm 2$ horas devem ficar a uma temperatura de $23 \pm 2 \stackrel{\circ}{\circ}$. e posteriores devem ser mantidas a temperatura de $55 \pm 2$ ㅇ C até aproximadamente 5 horas antes dos ensaios de compressão.

A NBR 12653:92, que específicas às exigências químicas e físicas para que um material seja considerado como uma pozolana. Na presente pesquisa foi utilizada a investigação do material com cimento aos 28 dias. As quantidades utilizadas para moldar os corpos de prova estão descritas na Tabela 3.

Tabela 3: Quantidades em massa necessárias para a moldagem de três corpos-de-prova cilíndricos.

\begin{tabular}{|l|l|l|}
\hline \multirow{2}{*}{ Material } & Massa necessária (g) \\
\cline { 2 - 3 } & Argamassa (A) & Argamassa (B) \\
\hline Cimento Portland - CP V & 312 & 202,8 \\
\hline Material Pozolânico & - & 92,82 \\
\hline Areia normal & 936 & 936 \\
\hline
\end{tabular}

Verificou-se que de acordo com a NBR 12653:92 (ABNT, 1992), que prescreve o índice de atividade pozolânica com cimento aos 28 dias, em relação ao controle, é 75 \% mínimo, portanto, o valor de 60,33\% encontrado não satisfaz o previsto na referida norma, em relação a amostra em estudo.

Como pode se observar analisando os resultados, houve uma menor evolução de resistência para a argamassa B em relação a argamassa A, e desta forma, obteve-se para argamassa com adição pozolânica uma menor resistência à compressão aos 28 dias (Tabela 4).

Tabela 4: Resultados da Resistência à Compressão dos Ensaios de Rompimentos dos corpos de provas cilíndricos.

\begin{tabular}{|l|l|}
\hline Tensão média argamassa A (MPa) & 18,76 \\
\hline Tensão média argamassa B (MPa) & 11,32 \\
\hline Índice de atividade pozolânica com cimento (\%) & 60,33 \\
\hline Água requerida argamassa A (ml) & 200 \\
\hline Água requerida argamassa B (ml) & 203 \\
\hline Água requerida (\%) & 101,5 \\
\hline
\end{tabular}

Os testes realizados para a resistência de compressão simples foram determinados com (06) unidades de tijolos por idade, e a média dos valores será expressa em Mpa. Para a realização dos testes de resistência, foram produzidos tijolos por fases distintas entre 7,14 e 28 dias de idades. Estipulou-se o final da pesquisa em 180 dias de idade, quando todos os ensaios no estado endurecido serão repetidos.

O resultado da pesquisa realizada nos estudos da caracterização do agregado reciclados da construção civil e demolição que foram coletados na empresa Eco Ambientais encontram-se habilitados para realizar a fabricação dos tijolos a serem desenvolvidos.

O material coletado diretamente do britador apresentou pequena porcentagem de areia fina, e com isso não há necessidade de introdução de areia do rio em sua composição. Portanto, o cimento é único elemento adicionado para obter resistência à compressão. Conforme os traços (1:7, 1:9, 1:11 e 1:20), nos 
estudos experimentais definidos para a fabricação dos tijolos, os resultados apresentados foram satisfatórios atendendo aos objetivos da norma, para a resistência e compressão axial simples. Constatou-se que os tijolos fabricados com cimento e resíduos da construção civil (RCC) são resistentes e absorvem muita água, mas não apresentam fissuras em sua estrutura.

Observou-se, ainda, que os agregados reciclados da construção civil e demolição estão aptos para serem empregados na fabricação de tijolos a serem utilizados na construção de habitação sem função estrutural, o qual foi o objetivo da pesquisa.

A propriedade que caracteriza a quantidade de água absorvida pelos vasos capilares é um fator que deve ser conhecido por quem o utiliza, pois define a possibilidade de umidade ascendente (REIS et al., 2013).

Na determinação da absorção de água imersão, verificou-se que o melhor desempenho foi o tijolo produzido no traço de 1:7, e como referência, o tempo de 6 horas apresentou 1,8 g/cm² de absorção, enquanto o tijolo produzido no traço 1:20, apresentou-se na mesma idade uma maior absorção de 3,3 g/cm². O resultado é coerente com o ensaio de absorção em que os tijolos produzidos nos traços 1:11 e 1:20, apresentaram as maiores taxas de absorção da ordem de 17,79\% e 16,57\% respectivamente. De acordo com NBR 8491:2012, em Tijolo de Solo-cimento, a absorção de água deve ser $\leq 20,0 \%$. Porém, em vários estudos, pesquisadores relatam que os materiais reciclados RCC sempre apresentaram alta taxa de absorção de água. Assim os estudos sobre os tijolos obtiveram resultado satisfatórios (Figura 3).

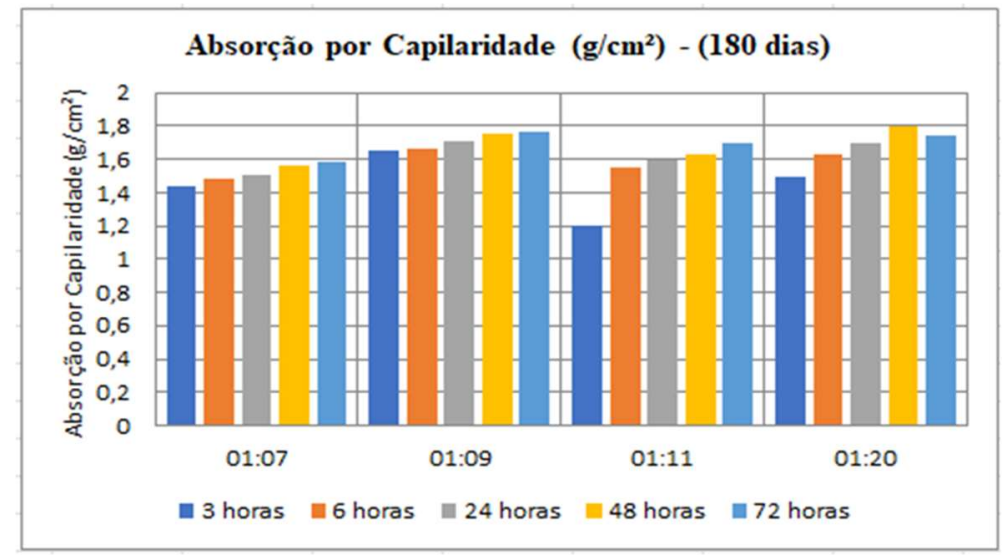

Figura 3: Determinação Absorção por Capilaridade $\left(\mathrm{g} / \mathrm{cm}^{2}\right)$ - (180 dias).

Conforme o resultado apresentado para a determinação da absorção por capilaridade aos 180 dias, conforme a NBR 9779:2012, verificou-se que o desempenho dos tijolos produzidos com referências de idades e horas indicadas, apresentou resultados coerentes para o ensaio. Como o material utilizado para a produção do tijolo em estudos é o agregado reciclado da construção civil, e sendo o cimento único elemento acrescentado na composição dos traços definidos para a determinação dos ensaios experimentais. Porém conforme os estudos pesquisadores relatam que os materiais reciclados de agregados RCC, sempre apresentaram alta taxa de absorção de água (Tabela 5).

Tabela 5: Absorção por capilaridade (método de teor de argamassa) - (geral).

\begin{tabular}{|c|c|c|c|c|c|}
\hline \multirow{2}{*}{\begin{tabular}{|l} 
Porcentagem \\
$51 \%$
\end{tabular}} & \multicolumn{5}{|c|}{ Absorção por Capilaridade $\mathrm{g} / \mathrm{cm}^{2}$} \\
\hline & $3 \mathrm{~h}$ & $6 \mathrm{~h}$ & $12 \mathrm{~h}$ & $48 \mathrm{~h}$ & $72 \mathrm{~h}$ \\
\hline 7 dias & 0,81 & 1,94 & 1,4 & 1,7 & 1,7 \\
\hline
\end{tabular}




\begin{tabular}{|l|l|l|l|l|l|}
\hline 14 dias & 1,43 & 1,44 & 1,37 & 1,45 & 1,45 \\
\hline 28 dias & 1,39 & 1,41 & 1,43 & 1,43 & 1,46 \\
\hline 180 dias & 1,45 & 1,58 & 1,63 & 1,69 & \\
\hline
\end{tabular}

Embora diferindo entre si quanto à capacidade de absorção de água, quanto à forma e textura superficial dos grãos e quanto à granulometria, todos os traços se mostraram viáveis para uso em tijolos de resíduo de construção civil.

Em relação aos materiais escolhidos para a pesquisa podemos dizer que:

- A escolha do agregado reciclado dos resíduos sólidos da construção civil para a fabricação dos tijolos foi acertada, tendo em vista que as variáveis físicas presentes nos resíduos são constituintes dos RCC. Alguns pesquisadores caracterizam os RCC como resíduos 'contaminados' por apresentarem vários materiais dos agregados da construção civil na sua composição;

- Em relação ao ensaio de absorção realizado segundo a NBR NM 9778:2009 (ABNT, 2001), na condição Saturada Superfície Seca do agregado reciclado de RCC, ficou evidenciada a dificuldade que muitos pesquisadores encontram para realizar esse ensaio, em virtude de o elevado nível de absorção possuir maior porosidade diferentes dos agregados naturais;

- A heterogeneidade do material é responsável pelas dificuldades no controle de qualidade do uso do resíduo que, por sua vez, depende muito da qualidade das fontes geradoras do resíduo.

Em relação aos procedimentos das moldagens dos tijolos, o processo 'artesanal' de moldagem da mistura homogênea dos RCC com o cimento pode incorrer em falhas do tipo:

- Os moldes metálicos da prensa hidráulica devem estar devidamente aquecidos para evitar a aderência ou a perda precoce de umidade pela mistura a ser moldada;

- Apesar da capacidade de prensagem hidráulica de seis toneladas (segundo manual do fabricante), o comando incorreto (pelo operador) do dispositivo de movimentação do pistão hidráulico pode produzir tijolos com espessuras diferentes, mais ou menos prensadas resultando em artefatos menos resistentes, mais porosos, etc.;

- A forma inadequada da retirada do tijolo após a moldagem também pode provocar fissuras internas no tijolo, afetando os resultados nos ensaios de resistência à compressão;

- Os resultados obtidos através dos ensaios de resistência à compressão dos tijolos, conforme os métodos experimentais para os respectivos traços são apresentados na tabela 19 - (Resistência à Compressão), os valores mínimos estabelecidos pela norma NBR 8492:2012 (ABNT, 2012) se enquadram na norma que direcionam os valores individuais $\geq 1,7 \mathrm{MPa}$, e para a média de resistência $\geq 2 \mathrm{MPa}$, com idade mínima de sete dias.

As diferenças nos resultados de ensaios de resistência à compressão apresentados num mesmo lote de amostras analisadas podem ser justificadas por falhas do tipo:

- Fissuras internas ocorridas na retirada dos tijolos após a moldagem. Dependendo da pressão exercida pelas mãos do operador no momento da retirada do tijolo, podem ocorrer fissuras internas não detectáveis externamente; 
- Falhas no capeamento dos tijolos para a realização dos ensaios de resistência. A falta de paralelismo entre as faces capeadas, segundo a NBR 10833:2012 (ABNT, 2012) pode influenciar o resultado do ensaio;

- Os períodos de 7, 14, 28 e 180 dias foram suficientes para demonstrar os desempenhos mecânicos dos tijolos pesquisados, porém verifica-se que a resistência dos tijolos fabricados aumenta gradativamente com o passar do tempo.

Em relação ao grau de pozolanicidade da amostra em estudo, constatou-se a não ocorrência, porém muito próximo do prescrito em norma.

Já a investigação da reação álcali-agregado, na amostra em estudo, conclui-se que o agregado reciclado do resíduo da construção civil (RCC) tem predisposição para uso na indústria da construção civil.

Diante dessa constatação, conclui-se que a técnica é viável e, econômica. Ambientalmente, a associação desses resíduos na produção de tijolos que poderiam ser incorporados aos processos construtivos da cadeia produtiva da construção civil é uma forma de mitigar o déficit habitacional do país e também dos descartes inadequados desses resíduos na natureza.

Como análise da viabilidade técnica e oportunidades na reutilização dos resíduos da construção civil, os tijolos de RCC representam uma alternativa em plena sintonia com as diretrizes do desenvolvimento sustentável. Como requerem baixo consumo de energia na fabricação dos tijolos, não há necessidade de extração da matéria-prima, dispensam o processo de queima e a emissão de poluentes na superfície terrestre.

Uma vez que os tijolos podem ser produzidos no próprio local da obra, outros aspectos a ser destacado é a possibilidade de racionalização do processo construtivo, por meio do uso de tijolos que possibilitam o uso das técnicas empregadas na alvenaria estrutural, proporcionando redução de desperdícios e diminuição no volume de entulho gerado. Desse modo, propiciam maior rapidez no processo construtivo, economia de materiais e de mão-de-obra, eliminam os rasgos nas paredes para a passagem de tubulações, visto que os tijolos possuem furos que ficam sobrepostos no seu assentamento e formam dutos por onde são passados os fios e as tubulações hidráulicas. Além disso, vale ressaltar que ainda há redução do consumo de argamassas de assentamento e de regularização.

\section{CONCLUSÕES}

O sucesso da reciclagem depende da habilidade de reutilização do resíduo no processo de origem como substituto de algum material: da habilidade de utilização como matéria-prima ou externa à planta e: da habilidade de segregar materiais recuperáveis e valiosos. A otimização de resíduos é um conceito novo de gerenciamento que envolve qualquer técnica, processo ou atividade que permite evitar, eliminar ou reduzir o resíduo na sua fonte, reusar ou reciclar os resíduos para vários propósitos. Desta forma, esta metodologia deve ser incorporada aos sistemas produtivos visando o fortalecimento industrial e o meio ambiente cada vez mais equilibrado. 


\section{REFERÊNCIAS}

ABNT. Associação Brasileira de Normas Técnicas. Procedimento (NBR 10833:2012) e (NBR 8492:2012). A fabricação de Tijolos de Solo-Cimento com Utilização de Prensa Manual ou Hidráulica - Análise dimensional, determinação da resistência à compressão e da absorção de água. ABNT, 2012.

ABNT. Associação Brasileira de Normas Técnicas. NBR NM 30:2001. Determinação da absorção de água por imersão Índice de vazios e massa específica - de acordo com a Norma brasileira (NBR 9778:2009) - (NBR 9779:2012) - Argamassa e Concreto Endurecidos - Determinação da Absorção de Água por Capilaridade. ABNT, 2001.

ABNT. Associação Brasileira de Normas Técnicas. NBR15116:2004 Agregados reciclados de resíduos sólidos da construção civil. Utilização em pavimentação e preparo de concreto sem função estrutural - Requisitos. ABNT, 2004.

ABNT. Associação Brasileira de Normas Técnicas. NBR 12653: Materiais pozolânicos - Requisitos. Rio de Janeiro: ABNT, 1992.

AMORIM, E. F.; QUEIROZ, H. S.; RIBEIRO, L. F. M.. Avaliação de Resíduos de Construção e Demolição de Obras Associado a um Solo Laterítico para Aplicação em Camadas de Pavimentação Asfáltica. In: CONGRESSO IBERO-LATINOAMERICANO DO ASFALTO, 16. Anais. Rio de Janeiro: IBP, 2011. p.102-112.

COSTA, J. S.. Agregados alternativos para argamassa e concreto produzidos a partir da reciclagem de rejeitos virgens da indústria de cerâmica tradicionais. Tese (Doutorado em Ciência e Engenharia de Matérias) Universidade Federal de São Carlos, São Carlos, 2006.

COSTA, J. S.; SANTANA, C. S.. Rejeito da indústria de cerâmica vermelha como agregado artificial para utilização na indústria da construção civil. In: CONGRESSO BRASILEIRO DE CONCRETO, 63. Anais. Santos: ABM, 2008.

FAVINI, A. C.; LUZARDO, E. M. A.; COSTA, J. S.. Avaliação do concreto produzido com rejeito de telha cerâmica vermelha.
In: CONGRESSO BRASILEIRO DE CERÂMICA, 53. Anais. Cuiabá: IFMT, 2009.

HELENE, P. R. L.. Manual de dosagem e controle do concreto. São Paulo: Pini, 1993.

JAILON, L.; POON, C. S.; CHIANG, Y. H.. Quantifying the waste reduction potencial of using prefabrication in building construction in Hong Kong. Waste Management, v.29, p.309-320, 2009.

LLATAS, C.. A model for quantifying construction waste in projects according to the European waste list. Waste Management, v.31, p.1261-1276, 2011.

LIMA, S. M.; ALBUQUerQUE, A. C.; SILVA, C. G.. Concreto autoadensável: Avaliação do efeito de resíduos industriais em substituição à areia (Parte 1). In: CONGRESSO BRASILEIRO DO CONCRETO, 54; SIMPÓSIO LATINOAMERICANO SOBRE CONCRETO AUTOADENSÁVEL, 1. Anais. Maceió: IBRACON, 2012.

NAGALLI, A.. Gerenciamento de resíduos sólidos na construção civil. São Paulo: Oficina de Textos, 2014.

PINTO, E. S.. Solo-Cimento compactação: proposta de métodos de ensaio para dosagem e caracterização física e mecânica. Dissertação (Mestrado) - Universidade estadual Paulista, Bauru, 2016.

REIS, S.; SANTOS, J.. Sustentabilidade com artefato de cimento produzido com resíduo da Construção Civil - RCC e Pó de pedra. In: SEMINÁRIO MATO-GROSSENSE DE HABITAÇÃO DE INTERESSE SOCIAL, 5. Anais. 2013.

YUAN, F.; SHEN, L.; LI, Q.. Emergy analysis of the recycling options for construction and demolition wast. Waste Management, v.31, n.11, p.2503-2511, 2011.

YUAN, H.; CHINI, A. R.; LU, Y.; SHEN, L.. A dynamic model for assessing the effects of management strategies on the reduction of construction and demolition waste. Waste Management, v.32, n.3, p.521-531, 2012.

A CBPC - Companhia Brasileira de Produção Científica (CNPJ: 11.221.422/0001-03) detém os direitos materiais desta publicação. Os direitos referem-se à publicação do trabalho em qualquer parte do mundo, incluindo os direitos às renovações, expansões e disseminações da contribuição, bem como outros direitos subsidiários. Todos os trabalhos publicados eletronicamente poderão posteriormente ser publicados em coletâneas impressas sob coordenação da Sustenere Publishing, da Companhia Brasileira de Produção Científica e seus parceiros autorizados. Os (as) autores (as) preservam os direitos autorais, mas não têm permissão para a publicação da contribuição em outro meio, impresso ou digital, em português ou em tradução. 